\title{
Erratum to: Storage Policies and Maintenance Support Strategies in Warehousing Systems
}

\author{
Xiaolong Guo
}

\section{Erratum to:}

X. Guo, Storage Policies and Maintenance Support Strategies

in Warehousing Systems, Springer Theses,

DOI 10.1007/978-981-10-1448-2

The book was inadvertently published with an incorrect affiliation. The correct affiliation is, School of Management, University of Science and Technology of China, Hefei, People's Republic of China. The book and the frontmatter has been updated.

The updated original online version for this book can be found at DOI 10.1007/978-981-10-1448-2

X. Guo $(\bowtie)$

School of Management, University of Science and Technology of China, Hefei,

People's Republic of China

e-mail: gxl@ustc.edu.cn 